\title{
Treatment of exercise-induced asthma with beclomethasone dipropionate in children with asthma
}

\author{
R. Petersen, L. Agertoft, S. Pedersen
}

Treatment of exercise-induced asthma with beclomethasone dipropionate in children with asthma. R. Petersen, L. Agertoft, S. Pedersen. (C) ERS Journals Ltd 2004.

ABSTRACT: A new hydrofluoroalkane-beclomethasone dipropionate (HFA-BDP) aerosol markedly increases drug delivery to the airways. Therefore, even low doses of HFA-BDP should be effective, and the present study assesses this.

A randomised, double-blind, crossover study was used to compare the effect of placebo, HFA-BDP $50 \mu \mathrm{g}$ or $100 \mu \mathrm{g}$ given q.d. $\left(\mathrm{QVAR}^{\mathrm{TM}}\right.$ Autohaler $^{\text {TM; }}$ 3M Pharmaceuticals, St. Paul, MN, USA) on exercise-induced bronchoconstriction and exhaled nitric oxide (eNO). After a 14-day run-in, 25 children (5-14 yrs old) entered three 4-week treatment periods, separated by a 1-week washout. After each period, the fall in forced expiratory volume in one second (FEV1), after an exercise test, and eNO were measured.

Significant treatment effects with no carry-over or period effects were seen for both eNO and maximum fall in FEV1 after exercise. Differences were seen between placebo (fall in FEV1=27.9\%; eNO=14.4 parts per billion (ppb)) and either dose of HFA-BDP, but not between the two active doses $(50 \mu \mathrm{g}$ : fall in $\mathrm{FEV1}=20.8 \%$, eNO=9.3 ppb; $100 \mu \mathrm{g}$ : fall in $\mathrm{FEV} 1=20.9 \%$, eNO $=8.9 \mathrm{ppb})$.

In conclusion, low q.d. doses of hydrofluoroalkane-beclomethasone dipropionate reduced exhaled nitric oxide and exercise-induced bronchoconstriction. Further studies are needed to assess whether $q . d$. administration of beclomethasone dipropionate is as effective as b.i.d. administration.

Eur Respir J 2004; 24: 932-937.
Dept of Paediatrics, Kolding Hospital, Kolding, Denmark.

Correspondence: R. Petersen, Dept of Paediatrics, Kolding Hospital, 6000 Kolding, Denmark

Fax: 4575535222

E-mail: sumsar68@hotmail.com

Keywords: Asthma

children

dose response

exercise

hydrofluoroalkane-beclomethasone dipropionate

nitric oxide

Received: December 232003

Accepted after revision: July 232004

This study was supported by $3 \mathrm{M}$ Pharmaceuticals, St. Paul, MN, USA.
Exercise-induced asthma is a common reflection of airway hyperresponsiveness in children with asthma. It may lead to quite marked impairment in everyday physical activities, even in children with mild asthma. International asthma management guidelines often recommend inhaled short-acting $\beta$ agonist therapy (as required) for this condition, since inhaled bronchodilators taken immediately prior to exercise effectively prevent the exercise-induced bronchoconstriction. However, this treatment does not influence the underlying airway hyperresponsiveness. Furthermore, children often do not know when they are going to exercise and, therefore, forget their medication, which is taken as needed.

Continuous treatment with inhaled corticosteroids (ICS) also offers good protection against exercise-induced bronchoconstriction [1-9]. In contrast to inhaled bronchodilators, ICS do not have to be taken immediately prior to the exercise, and they modify airway hyperresponsiveness. The clinically effective dose for exercise-induced asthma may be different from the dose required to control other asthma outcomes [1, $5,9-12]$, and the shape of the dose-response curve for exercise-induced bronchoconstriction may also be different from that of other asthma outcomes. Therefore, more information is needed about the dose-response relationships of the protection of various ICS against exercise-induced bronchoconstriction, in order to ensure optimum therapy with ICS against this condition and to establish what doses of ICS are needed to decrease the bronchial responsiveness so that exercise-induced bronchoconstriction can be adequately controlled.
A new formulation of hydrofluoroalkane-beclomethasone dipropionate (HFA-BDP; QVAR ${ }^{\mathrm{TM}}$; $3 \mathrm{M}$ Pharmaceuticals, St. Paul, MN, USA) produces an extra-fine aerosol spray that, compared with conventional inhalers, increases the amount of drug delivered to the lungs [13-20]. Since more drug per puff is delivered to the site of the disease, it seems reasonable to assume that even very low doses of HFA-BDP will provide a significant therapeutic response. The present dose-response study was designed to assess the effect of low doses (50 or $100 \mu \mathrm{g}$ q.d.) of HFA-BDP extra-fine aerosol on exhaled nitric oxide (eNO) and the protection of exerciseinduced bronchoconstriction in children with exerciseinduced asthma.

\section{Methods}

\section{Patients and methods}

Children aged 6-15 yrs with a history of exercise-induced bronchoconstriction were recruited from the current authors' outpatient asthma clinic (Dept of Paediatrics, Kolding Hospital, Kolding, Denmark). In order to be included in the study, the patients had to have a resting forced expiratory volume in one second (FEV1) of $\geqslant 70 \%$ of predicted normal [21], and a documented decrease in FEV1 of $\geqslant 15 \%$ after a standard exercise challenge test at a screening visit.

The study was approved by the regional ethics committee. 
Each child gave informed oral assent, and the child's parent or legal guardian gave written informed consent in accordance with the current version of the Declaration of Helsinki.

Patients who were found eligible at the screening visit entered a 2-week run-in period, during which no regular asthma medication was allowed. At the end of this period, each patient returned to the clinic for measurement of eNO, followed by an exercise challenge test. At the end of the runin, patients who also demonstrated a maximum fall of $\geqslant 15 \%$ in FEV1 post-exercise entered the trial, which was a randomised, double-blind, placebo-controlled, single-centre crossover study, consisting of three 4-week study periods, each separated by a 1-week washout. The following treatments were given during the double-blind periods: HFA-BDP $50 \mu \mathrm{g}$, HFA-BDP $100 \mu \mathrm{g}$, and placebo. Treatments were administered q.d. (at approximately the same time each evening) from a breath-actuated device (Autohaler ${ }^{\mathrm{TM}}$; $3 \mathrm{M}$ Pharmaceuticals). Patients were trained in the correct use of the Autohaler before they entered the study. Compliance was assessed using the weights of the canisters. The predicted weights and weights after actual use were compared.

Throughout the study, each patient continued to use a short-acting $\beta$-agonist as needed to treat asthma symptoms; no other asthma medication was allowed. Measurements of eNO and an exercise challenge test were performed at the end of each treatment period. Diary card recordings of peak expiratory flow (PEF), asthma symptoms and sleep disturbance scores, and inhaled short-acting $\beta$-agonist use were undertaken throughout the study.

\section{Exercise challenge test}

Each patient exercised on a treadmill with a slope of $12 \%$. The speed was adjusted so that the patient's heart rate reached or exceeded 180 beats $\cdot \mathrm{min}^{-1}$ during the last $5 \mathrm{~min}$ of exercise. During the exercise challenge test, the patient wore a nose-clip and inhaled cold $\left(-5^{\circ} \mathrm{C}\right)$ dry air through a face mask. The maximum duration of the exercise challenge test was 8 min. Post-exercise spirometry was performed at 2, 4, 6, 10, 15 and 20 min after completion.

\section{Measurement of exhaled nitric oxide}

Measurement of eNO was performed at the end of the runin (start of period 1), and at the end of periods 1, 2 and 3. The measurements were performed using a chemiluminescence analyser, following the method described by KHARITONOV et al. [22]. After a full inhalation, the patient exhaled slowly through a mouthpiece (exhalation flow rate: $200 \mathrm{~mL} \cdot \mathrm{s}^{-1}$ ) that bypassed the analyser. The mouthpiece had moderate resistance to ensure that the soft palate was lifted up and partially closed the nasopharynx. The eNO was sampled from a sidearm attached to the mouthpiece. Patients did not use a nose-clip during this procedure. The eNO value was automatically calculated from the chosen part of the curve for the last $10 \mathrm{~s}$, corresponding to the plateau of the exhaled end level. The mean of three measurements was calculated. The analyser was calibrated and the eNO concentration of the ambient air was measured on each study day.

\section{Statistics}

The analysis population consisted of all patients who had evaluations performed for at least two treatment periods (thus allowing at least one pairwise treatment difference to be estimable for that patient). For each exercise challenge, the maximal percentage fall in FEV1 (L) following exercise was calculated as:

$$
\begin{aligned}
& ((\text { FEV1 before exercise }- \text { minimum FEV1 } \\
& \text { following exercise }) / \text { FEV1 before exercise }) \times 100 \%
\end{aligned}
$$

The maximal percentage fall in FEV1 in each period was compared using an ANOVA with sequence, patient within sequence, treatment, and period as factors in the model. If the treatment effect was statistically significant at $\mathrm{p}<0.05$, multiple comparisons were done using Tukey's method. A $95 \%$ confidence interval (CI) was calculated for each pairwise difference in the means. The percentage fall from pre-exercise at each time point $(\mathrm{t})$ was calculated as:

\section{((FEV1 before exercise - FEV1 at time $t) / F E V 1$}

before exercise) $\times 100 \%$

The mean percentage fall in FEV1 was plotted against time for each treatment. The area under the curve (AUC) for the percentage fall in FEV1 from exercise over the 20-min period was calculated using a trapezoidal rule. The AUC was analysed using the same methods as the primary response.

\section{Pre-exercise pulmonary function tests}

The percentage change from baseline in pre-exercise FEV1 at the end of each period was calculated as:

\section{((Pre-exercise FEV1 at end of period - pre-exercise}

FEV1 at run-in)/pre-exercise FEV1 at run-in) $\times 100 \%$

The treatments were compared using the same ANOVA model as the primary response.

\section{Exhaled nitric oxide levels}

The eNO levels were compared at the end of each period using the same methods as the primary response.

\section{Sample size}

A sample size of 24 compliant patients completing all three periods was determined, based upon an estimate of the within-patient standard deviation (SD) of $9.5 \%$ for the maximal change from baseline in FEV1 following exercise in paediatrics [23]. Given this estimate, a sample size of 24 patients in a crossover design would provide $\geqslant 80 \%$ power for detecting a difference in at least one of the treatments of $8 \%$ at the $\alpha=0.05$ level.

\section{Results}

A total of 68 patients (ages 6-15 yrs, 22 females and 46 males) were screened with lung function, exercise test and eNO measurement. In total, 20 males and seven females were included in the study. Failure to meet the entry criterion of a fall of $\geqslant 15 \%$ in FEV1 post-exercise was the most common reason for noninclusion ( 37 out of 41 ). A total of 25 patients completed all three periods. Two patients were discontinued in period 1; the first (placebo) because of an asthma exacerbation and the second because of a toe fracture. The mean age was 10.6 yrs (range 6.0-14.0 yrs) and mean FEV1\% predicted was $87.2 \%$ (range $66-116 \%$ ). 
Compliance was assessed by weighing canisters. Mean \pm SD compliance with the medication was $>90 \%$, and there was no

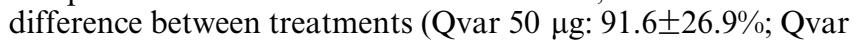
$100 \mu \mathrm{g}$ : 91.3土38.5\%; placebo: $92.6 \pm 39.0 \%$ )

\section{Exercise}

The primary efficacy variable was the maximum percentage fall in FEV1 following exercise. A statistically significant treatment effect was seen $(\mathrm{p}=0.038)$, with no significant period or carry-over effect or difference between the two BDP doses (table 1). AUC for the percentage fall was also greater for placebo compared with HFA-BDP, and a significant treatment effect was found ( $\mathrm{p}=0.003)$. The AUCs $(95 \% \mathrm{CI})$ for the three periods were: $351 \%$ minimum $(237-465)$ after placebo; $228 \%$ minimum (153-303) after BDP $50 \mu \mathrm{g}$, and $196 \%$ minimum (125-267) after BDP $100 \mu \mathrm{g}$. In the pairwise comparisons, both BDP doses were better than placebo $(p<0.05)$. No statistically significant differences were seen between the two BDP doses. The conclusions for maximum percentage fall in forced mid-expiratory flow (FEF25-75\%) and AUC for the percentage fall in FEF 25-75\% after exercise were very similar to the conclusions for FEV1.

Both BDP doses improved pre-exercise FEV1 significantly $(\mathrm{p}<0.05)$ by $\sim 6 \%$ pred. Pre-exercise FEV1 (95\% CI) during the three periods were $86.8 \%(82.7-90.9)$ after placebo, $90.2 \%$ (86.1-94.3) after $50 \mu \mathrm{g}$ BDP, and 90.5\% (86.7-94.3) after $100 \mu \mathrm{g}$ BDP. Similar conclusions were found for pre-exercise FEF $25-75 \%$, which was improved by $20 \%$ with both HFABDP doses. There was no correlation between increases in FEV1 and reductions in post-exercise fall in FEV1. FEV1 decreased $>15 \%$ after exercise in 16 out of 25 patients in the placebo group, and 14 out of 25 in both treatment groups.

FEV1 \% pred $(95 \% \mathrm{CI})$ after exercise was $62.4 \%(58.7-66.1)$ after placebo, 71.4\% (68.0-74.8) after BDP $50 \mu \mathrm{g}$, and $71.6 \%$ (68.0-75.2) after BDP $100 \mu \mathrm{g}$. Calculated in this way, the treatment effect was smaller, but still statistically significant ( $\mathrm{p}=0.049)$ with no significant period or carry-over effect or difference between the two BDP doses.

\section{Exhaled nitric oxide}

Mean eNO levels after HFA-BDP treatment were approximately half the levels seen after placebo $(p<0.0001$; table 1$)$.

In the pairwise comparisons, significant differences were seen between the two BDP doses and placebo $(p<0.05)$, but no differences between the two BDP doses.

A statistically significant correlation was seen between eNO and the maximum percentage fall in FEV1 $(\mathrm{p}=0.012)$ and maximum percentage fall in $\mathrm{FEF} 25-75 \% \quad(\mathrm{p}=0.010)$ after placebo treatment (fig. 1). These correlations were no longer statistically significant after HFA-BDP treatments. The results were exactly similar for the correlations between placebo eNO and the AUC fall in FEV1 ( $\mathrm{p}=0.024)$ and FEF $25-75 \%(\mathrm{p}=0.017)$.

In total, 17 patients had allergic asthma and eight had nonallergic asthma. As a result of the low numbers, no statistical comparison was made between the two groups. The changes in FEV1 \% pred post-exercise in the allergic group were $27.6 \%, 18.8 \%$ and $19.8 \%$ after placebo, 50 and $100 \mu \mathrm{g}$ BDP; the corresponding values for the nonallergic group were $20.6 \%, 17.1 \%$ and $14.9 \%$, respectively. The eNO values in the allergic group were $16.6,10.7$ and $9.8 \mathrm{ppb}$; the corresponding values for the nonallergic group were $10.2,6.5$ and $7.2 \mathrm{ppb}$, respectively.

The asthma was mild and the patients reported few asthma problems during placebo treatment. Neither dose of HFABDP had any statistically significant effects on PEF, asthma symptom and sleep disturbance scores, or the use of inhaled short-acting $\beta$-agonist.

Few patients reported adverse events during treatment: HFA-BDP $50 \mu \mathrm{g}(\mathrm{n}=1)$, HFA-BDP $100 \mu \mathrm{g}(\mathrm{n}=4)$, or placebo $(n=3)$. Adverse events associated with the respiratory system were the most common, and they occurred most frequently with placebo $(n=3)$ compared with HFA-BDP $50 \mu \mathrm{g}(\mathrm{n}=1)$ and HFA-BDP $100 \mu \mathrm{g}(\mathrm{n}=1)$. No adverse events were considered to be associated with the study medication.

\section{Discussion}

The present findings showed that a short course of low-dose HFA-BDP exerted a significant reduction in airway hyperreactivity to exercise in children with mild intermittent or mild persistent asthma. This corroborates the findings of other studies with low doses of budesonide or fluticasone propionate in children with mild asthma [1-5]. However, the magnitude of the protective effects in these studies seemed greater than the effects achieved in the present study. Thus, budesonide 100 or $200 \mu \mathrm{g} \cdot \mathrm{day}^{-1}$ given either q.d. or b.i.d. reduced the post-exercise fall in lung function from $\sim 25 \%$ to $5-7 \%$ [3], and fluticasone propionate $100 \mu \mathrm{g}$ b.i.d. from $33 \%$

Table 1.-Exercise challenge: forced expiratory volume in one second (FEV1) parameters and pre-exercise exhaled nitric oxide (eNO) during the various study periods

\begin{tabular}{lcc}
\hline & Maximum \% fall in FEV1 & eNO ppb \\
\hline Subjects $\mathrm{n}$ & 25 & 25 \\
Run-in & $31.0 \pm 15.3(24.7-37.3)$ & $16.0 \pm 10.1(11.8-20.2)$ \\
Placebo & $27.9 \pm 15.6(21.4-34.3)$ & $14.4 \pm 9.3(10.5-18.4)$ \\
HFA-BDP $50 \mu \mathrm{g}$ & $20.8 \pm 11.2(16.2-25.4)$ & $9.3 \pm 6.8(6.5-12.1)$ \\
HFA-BDP $100 \mu \mathrm{g}$ & $20.9 \pm 13.1(15.5-26.4)$ & $8.9 \pm 6.6(6.2-11.6)$ \\
Pairwise differences & & $-5.0 \pm 6.8(-7.9--2.1)$ \\
$50 \mu \mathrm{g}$ and placebo & $-7.0 \pm 16.6(-13.9--0.2)$ & $-5.4 \pm 7.2(-8.5--2.4)$ \\
$100 \mu \mathrm{g}$ and placebo & $-6.9 \pm 13.4(-12.4-1.4)$ & $-0.4 \pm 3.5(-1.8-1.0)$ \\
$100 \mu \mathrm{g}$ and $50 \mu \mathrm{g}$ & $0.1 \pm 15.5(-6.2-6.5)$ & $<0.0001$ \\
p-Values of effects & 0.0387 & 0.8349 \\
$\quad$ Treatment & 0.2228 & 0.2022 \\
Period & 0.1308 & \\
Carry-over & & \\
\hline
\end{tabular}

Data are presented as $\mathrm{n}$ and mean $\pm \mathrm{SD}$ (95\% confidence interval). ppb: parts per billion; HFA-BDP: hydrofluoroalkane-beclomethasone dipropionate. 

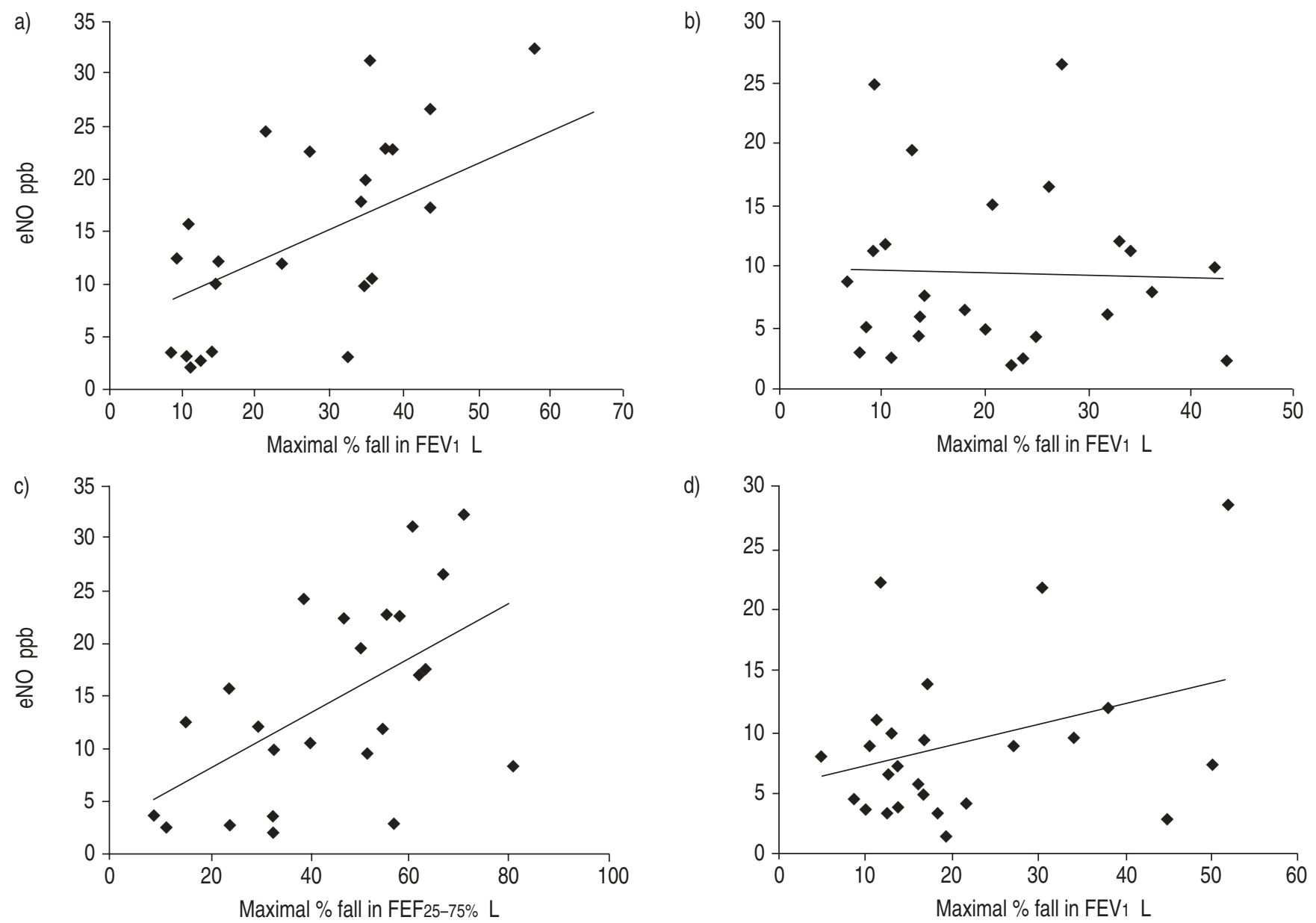

Fig. 1. - Correlation between exhaled nitric oxide (eNO) and maximal \% fall in forced expiratory volume in one second (FEV 1$)$ and forced midexpiratory flow $\left(\mathrm{FEF}_{25-75 \%}\right.$ ) after exercise. Correlation coefficients between eNO and the maximal \% fall in FEV1 for placebo (a; $\left.\mathrm{p}=0.012\right)$ and between eNO and the maximal fall in $\mathrm{FEF}_{25-75 \%}$ for placebo (c; $\mathrm{p}=0.010$ ) were calculated. Correlation coefficients for 50 (b) and $100 \mu \mathrm{g}$ (d) hydrofluoroalkane-beclomethasone dipropionate q.d. with FEV1 were not significant ( $>>0.05$ ). ppb: parts per billion.

to $9 \%$ [5]. In the studies with budesonide, the protective effect of the drug was the same whether it was administered q.d. or b.i.d. In light of these findings, it was surprising that the fall in FEV1 after exercise was only reduced from $28 \%$ to $21 \%$ in the present study, considering that the Autohaler used delivers twice as much drug to the intrapulmonary airways as budesonide Turbuhaler [13-18, 20, 24], and at least three times as much as the fluticasone propionate pressurised metered-dose inhaler [15, 17-20, 24] in both children and adults. The reason for this is not clear. One possibility could be that the increased and more peripheral lung deposition from Autohaler was not associated with a similar increase in clinical effect. This seems unlikely, since several studies in children and adults using other outcomes have found increased clinical effects from Autohaler, as compared with less effective delivery devices [25-29]. Another reason could be that BDP is not suitable for q.d. administration. No other studies have dosed BDP q.d. In the current study, it was always administered in the evening and the exercise challenge was performed in the afternoon on the following day. This may have been too long an interval for a good protection; further studies are needed to assess this. Poor compliance could not explain the rather small effect. It is also unlikely that the treatment duration was too short, since the maximum protective effect is already achieved after $1-2$ weeks treatment [30].
Normally, a marked clinical effect is seen at low doses of an ICS, and, often, a four-fold increase in dose is required to produce an additional statistical improvement in an asthma outcome [1], so it might not be surprising that no differences were found between the two BDP doses used in the present study. However, the ICS dose-response curve for protection against exercise-induced bronchoconstriction may be different from the dose-response curves for other outcomes [1, 5, 9-12], and statistically significant differences in protective effects between doubling doses of ICS have been reported earlier in children with moderate and severe exercise-induced asthma [1], even if the lowest dose produced a 50\% reduction in the post-exercise fall in FEV1. Therefore, the current authors would have expected to find a dose-response relationship in protective effects against exercise-induced bronchoconstriction, particularly because there was still room for improvement after the low dose: perhaps this was also due to the q.d. dosing? An additional dose of HFA-BDP of $200 \mu \mathrm{g}$ q.d. might have elucidated this, but an extra treatment period would have been elusive.

The children selected for this study had mild, intermittent or persistent asthma, and a history of clinically important exercise-induced bronchoconstriction. The diary card data confirmed the mildness of the disease. Almost no symptoms and $\beta$-agonist rescue therapy were reported and peak flows were normal. There was virtually no room for improvement in 
these parameters. Therefore, it was not surprising that the active treatments were not associated with any statistically significant effects on these outcomes. In contrast, pre-exercise values of FEV1 and FEF25-75\% were somewhat reduced, and both doses of BDP caused significant improvements in these outcomes by $\sim 5$ and $20 \%$ pred, respectively. For these outcomes, it was not surprising that dose-response effects could not be demonstrated: there was little room for improvement after the lowest dose. Lung function was close to normal after that dose.

To evaluate a possible link between the therapeutic effect on airway hyperreactivity and on airway inflammation, levels of eNO were measured pre-challenge. The effects of HFABDP on eNO were very similar to the protective effects on exercise-induced bronchoconstriction, except that the lowest dose seemed to have a somewhat greater effect on eNO. Levels of eNO were not normalised (in the current authors' laboratory, normal values are $\leqslant 5 \mathrm{ppb}$ ) and no dose response was seen. Interestingly, significant correlations between eNO and fall in FEV1 or FEF25-75\% after exercise were only seen during run-in and after placebo treatment, but not during treatment with BDP. This suggests that the BDP doseresponse curves for these two outcomes may be different. Further studies are needed to assess that, but perhaps a more peripheral deposition of drug in the airways is more important for eNO than for protection against exerciseinduced bronchoconstriction. The fall in lung function after exercise and the eNO levels were numerically greater in patients with allergic asthma than in children with nonallergic asthma. However, the low number of nonallergic patients precluded any firm conclusions about these differences or potential differences in treatment effects. Further studies are required to assess this.

\section{Conclusion}

Low q.d. doses of hydrofluoroalkane-beclomethasone dipropionate extra-fine aerosol (50 or $100 \mu \mathrm{g})$ reduced exhaled nitric oxide and improved lung function and exercise tolerance in children with exercise-induced asthma. No doseresponse effects were seen. Further studies are needed to assess whether q.d. administration of beclomethasone dipropionate is as effective as b.i.d. administration.

\section{References}

1. Pedersen S, Hansen OR. Budesonide treatment of moderate and severe asthma in children: a dose-response study. J Allergy Clin Immunol 1995; 95: 29-33.

2. Jonasson G, Carlsen K-H, Blomqvist P. Clinical efficacy of low-dose inhaled budesonide once or twice daily in children with mild asthma not previously treated with steroids. Eur Respir J 1998; 12: 1099-1104.

3. Jonasson G, Carlsen K-H, Hultquist C. Low-dose budesonide improves exercise-induced bronchospasm in schoolchildren. Pediatr Allergy Immunol 2000; 11: 120-125.

4. Jonasson G, Carlsen K-H, Jonasson C, Mowinckel P. Lowdose inhaled budesonide once or twice daily for 27 months in children with mild asthma. Allergy 2000; 55: 740-748.

5. Hofstra WB, Neijens HJ, Duiverman EJ, et al. Dose-responses over time to inhaled fluticasone propionate treatment of exercise- and methacholine-induced bronchoconstriction in children with asthma. Pediatr Pulmonol 2000; 29: 415-423.

6. Waalkens HJ, van Essen-Zandvliet EE, Gerritsen J, Duiverman EJ, Kerrebijn KF, Knol K. The effect of an inhaled corticosteroid (budesonide) on exercise-induced asthma in children. Dutch CNSLD Study Group. Eur Respir J 1993; 6: 614-616.
7. Vidal C, Fernandez-Ovide E, Pineiro J, Nunez R, GonzalezQuintela A. Comparison of montelukast versus budesonide in the treatment of exercise-induced bronchoconstriction. Ann Allergy Asthma Immunol 2001; 86: 655-658.

8. Vathenen AS, Knox AJ, Wisniewski A, Tatersfield AE. Effect of inhaled budesonide on bronchial reactivity to histamine, exercise, and eucapnic dry air -hyperventilation in patients with asthma. Thorax 1991; 46: 811-816.

9. Freezer NJ, Croasdell H, Doull IJ, Holgate ST. Effect of regular inhaled beclomethasone on exercise and methacholine airway responses in school children with recurrent wheeze. Eur Respir J 1995; 8: 1488-1493.

10. Pedersen S. Comparing inhaled glucocorticosteroids. Allergy 1999; 54: Suppl. 49, 42-50.

11. Jatakanon A, Kharitonov S, Lim S, Barnes PJ. Effect of differing doses of inhaled budesonide on markers of airway inflammation in patients with mild asthma. Thorax 1999; 54: 108-114.

12. Beck-Ripp J, Griese M, Arenz S, Köring C, Pasqualoni B, Bufler P. Changes of exhaled nitric oxide during steroid treatment of childhood asthma. Eur Respir J 2002; 19: 10151019.

13. Agertoft L, Pedersen S. Lung deposition and systemic availability of fluticasone diskus and budesonide turbuhaler. Am J Respir Crit Care Med 2003; 168: 779-782.

14. Wildhaber JH, Devadason SG, Wilson JM, et al. Lung deposition of budesonide from turbuhaler in asthmatic children. Eur J Pediatr 1998; 157: 1017-1022.

15. Devadason SG, Huang T, Walker S, Troedson R, Le Souef PN. Distribution of technetium-99m-labelled QVAR delivered using an Autohaler device in children. Eur Respir $J$ 2003; 21: 1007-1011.

16. Thorsson L, Edsbacker S, Conradson TB. Lung deposition of budesonide from Turbuhaler is twice that from a pressurized metered-dose inhaler P-MDI. Eur Respir $J$ 1994; 7: 1839-1844.

17. Leach CL, Davidson PJ, Boudreau RJ. Improved airway targeting with the CFC-free HFA-beclomethasone metereddose inhaler compared with CFC-beclomethasone. Eur Respir J 1998; 12: 1346-1353.

18. Leach CL, Davidson PJ, Hasselquist BE, Boudreau RJ. Lung deposition of hydrofluoroalkane-134a beclomethasone is greater than that of chlorofluorocarbon fluticasone and chlorofluorocarbon beclomethasone. Chest 2002; 122: 510516.

19. Devadason SG, Everard ML, MacEarlan C, et al. Lung deposition from the Turbuhaler in children with cystic fibrosis. Eur Respir J 1997; 10: 2023-2028.

20. Thorsson L, Edsbacker S, Kallen A, Lofdahl CG. Pharmacokinetics and systemic activity of fluticasone via Diskus and pMDI, and of budesonide via Turbuhaler. $\mathrm{Br} J$ Clin Pharmacol 2001; 52: 529-538.

21. Polgar G, Promadhat V. Pulmonary function testing in children: techniques and standards. Philadelphia, W.B. Saunders Co., 1971; pp. 170-180, 254.

22. Kharitonov S, Alving K, Barnes PJ. Exhaled and nasal oxide measurements: recommendations. The European Respiratory Society Task Force. Eur Respir J 1997; 10: 1683-1693.

23. Hofstra WB, Sont JK, Sterk PJ, Neijens HJ, Kuethe MC, Duiverman EJ. Sample size estimation in studies monitoring exercise-induced bronchoconstriction in asthmatic children. Thorax 1997; 52: 739-741.

24. Soria I, Harrison LI, Machacek JH, Cline AC, Stampone PA. Beclomethasone relative availability of oral versus inhaled beclomethasone dipropionate from an HFA-134a metered dose inhaler. Biopharm Drug Dispos 1998; 19: 297302.

25. Worth H, Muir JF, Pieters WR. Comparison of hydrofluoroalkane-beclomethasone dipropionate Autohaler with budesonide Turbuhaler in asthma control. Respiration 2001; 68: 517-526.

26. Reichel W, Dahl R, Ringdal N, Zetterstrom O, van den 
Elshout FJ, Laitinen LA. Extrafine beclomethasone dipropionate breath-actuated inhaler (400 micrograms/day) versus budesonide dry powder inhaler (800 micrograms/day) in asthma. Int $J$ Clin Pract 2001; 55: 100-106.

27. Nayak A, Lanier R, Weinstein S, Stampone P, Welch M. Efficacy and safety of beclomethasone dipropionate extrafine aerosol in childhood asthma: a 12-week, randomized, double-blind, placebo-controlled study. Chest 2002; 122: 1956-1965 (Erratum in: Chest 2003; 123: 2164).

28. Szefler SJ, Warner J, Staab D, et al. Switching from conventional to extrafine aerosol beclomethasone dipropionate therapy in children: a 6-month, open-label, randomized trial $J$ Allergy Clin Immunol 2002; 110: 45-50.

29. Farmer IS, Middle M, Savic J, Perri VL, Herdman MJ. Therapeutic equivalence of inhaled beclomethasone dipropionate with CFC and non-CFC (HFA 134a) propellants both delivered via the Easibreathe inhaler for the treatment of paediatric asthma. Respir Med 2000; 94: 57-63.

30. Shapiro G, Bronsky EA, LaForce CF, et al. Dose-related efficacy of budesonide administered via a dry powder inhaler in the treatment of children with moderate to severe persistent asthma. J Pediatr 1998; 132: 976-982. 